\title{
DiTenun, Smart Application Producing Ulos Motif
}

\author{
Arlinta C. Barus ${ }^{1^{*}}$, Marianna Simanjuntak ${ }^{2}$, and Verawati Situmorang ${ }^{3}$ \\ ${ }^{1,3}$ Teknik Informatika, Institut Teknologi Del, Laguboti Sumatera Utara \\ ${ }^{2}$ Management Rekayasa, Institut Teknologi Del, Laguboti Sumatera Utara
}

\begin{abstract}
Indonesia is a country which is rich of various traditional cultures and values. One of its representation is traditional woven clothes (well known in Indonesian as kain tenun) which is wide spread throughout Indonesian regions. To support the traditional woven industry, as a relevancy to the industry 4.0 era, we develop DiTenun which is a multiplatform application that is able to produce new motifs of traditional woven intelligently using machine learning approach. The presence of the apps aims to support the growth of traditional weaving industry particularly the small and medium scale ones. The dissemination of the apps is very challenging as traditional woven centers are mostly located in rural area where the digital world has been rarely accessed. In this paper, we present "Ulos" as a case study in the utilization of DiTenun. The implementation of the sustainability of the Ulos industry by DiTenun needs to be adjusted to the development of the industrial era 4.0. Ulos is a traditional woven cloth from Batak tribe, which is located in several rural regions surrounding Toba highland in North Sumatera Utara province. The workflow for producing an item that is marketable is to produce woven fabrics with motifs that have been produced by smart devices. The results of DiTenun can have an impact on the technology produced and on the social life and culture of the weavers. The study shows how DiTenun is designed to support Ulos weavers in creating new motifs of Ulos and to support the economy of relevant small and medium scale industry of Ulos.
\end{abstract}

\section{Introduction}

Indonesia is known as a country that is rich in art and culture. One element of the culture is weaving. Weaving is a handicraft in the form of fabric made from yarn (cotton, silk, etc.) by entering threads transversely on a tool and made in areas such as Sumatra, Java, Palembang and Kalimantan. Related to weaving products from various regions, this study examines the weaving results of the North Sumatra region, Ulos.

Ulos is a woven fabric typical of the Batak people who show affection between parents and children, or between someone and other people (Aritonang, 2015). Ulos has a variety of types and motifs that describe its own meaning according to the nature, circumstances, functions, and traditional ceremonies performed. Besides being used for traditional events,

* Corresponding author: author@email.org 
Ulos are also used as assets such as table cloth, wall decoration, etc. (Barus, 2015). In addition to traditional ceremonies, Ulos has been produced into fashion products and motifs that can be used into several daily supplies.

The Ulos motif used by weavers today is the Ulos motif that was discovered many years ago and is continuing to be used today. Thus the motif poured on Ulos are the same motif and are produced repeatedly. The same Ulos motif reduces the image and creativity in making Ulos motifs themselves. The various and many Ulos motifs will certainly produce more ideas that can be poured into various weaving products.

This paper presents our work to develop apps DiTenun which has a main function to generate Ulos motif automatically. The generation makes use machine learning concepts and image processing algorithms to learn about Ulos motifs and to produce new Ulos motifs but still have cultural values contained in the Ulos itself. In details, this paper discusses how DiTenun is produced and knows the role of DiTenun in the lives of industrial weavers in industrial 4.0

\section{Literature Survey}

\subsection{Ulos}

Ulos is a type of traditional woven fabric originating from the Batak tribe which consists of various types, patterns or motifs and sizes. Ulos is a Batak woven scarf, usually used in traditional ceremonies (marriage, entering a house, death, etc.) (Wikipedia).

Ulos was used by the Batak people as body warmers, but now Ulos cloth is used for other aspects, for example, it is used as Batak ceremonial clothing, Batak community performing arts, and so on. Ulos Batak community consists of various types, namely Toba Ulos Batak, Simalungun, Karo, Pakpak-Dairi and Mandailing-Angkola. Ulos motifs are very diverse, beautiful, unique, and rich in historical and cultural values. Ulos fabric has not been widely developed in the industry because of its traditional and manual workmanship. In addition, the development of the design still revolves around certain weaving motifs for traditional ceremonies. Even though there is so much economic potential that can be developed from Ulos cloth (Pilialang, 2011).

\subsection{Rural Area}

There is no single best defenition that measures theoretical construct of Rural. The variability in rural defenition is not inherent limitation of rural research, failure to adequate define and describe rural makes it difficult, if not impossible, to confidently make comparisons, and interpatation (Gustavo Anríquez, 2007). Rural areas are more integrated into the world economy, as a result both of liberalisation and improved infrastructure.

\subsection{Industry 4.0}

The implementation of the sustainability of the Ulos industry by DiTenun needs to be adjusted to the development of the industrial era 4.0 (Mohelsska \& Sokolova, 2018). States that Industry 4.0 is based on a boom in digitalization, robotics and automation, and is characterized by a blend of information technology and production processes and in intelligent ways that are characteristic of autonomous machines are called series Internet of Things (IoT) (Toma \& Popa, 2018). IoT cannot be separated from the industrial era 4.0, the fourth industrial revolution with intelligent digitalization and automation of value chain products and processes. This is largely based on that the Internet has brought a number of 
changes to manufacturing and maintenance in the industry, from reducing the production cycle to the automation of maintenance of machinery and equipment, including real and virtual world production integration, where products, production facilities, people and objects are joined by devices software embedded into intelligent and distributed systems (Wilhelm et al, 2018).

\subsection{Machine Learning}

Machine learning has developed from learning computational theory and pattern recognition. The most effective method is used in data analysis to predict things based on the model and algorithm. This model makes researchers and developers manage patterns to get results and good decision making. For some patterns that have been lost can appear by studying the history of data. The model is based on results collected from training data and it is very difficult to get accurate predictions based on the algorithm developed (Sheena Angra, 2017).

The machine learning technique implemented in DiTenun is image processing. The image can be defined as a two-dimensional function $\mathrm{f}(\mathrm{x}, \mathrm{y})$ where $\mathrm{x}$ and $\mathrm{y}$ are the coordinate fields, and the amplitude of $\mathrm{f}$ in the $\mathrm{x}$ coordinate pair, $\mathrm{y}$ is called the intensity of the image at that point. When the value of $x, y$ and the amplitude value are known we can call it a digital image. Digital image processing refers to the processing of digital images, meaning by using a computer (Gonjales).

\section{Analisys and Design}

\subsection{Art and Technology Collaboration}

Traditional crafts in this technological progress are slowly because there are not many researchers and innovators who see the potential for technological development, industrial design, preservation of cultural history, and economics in traditional craft industries. In addition, the lack of access to information and access to technology that can be reached by artisans who live in isolated areas far enough from the city center is not helpful at all in utilizing traditional textile craft innovations, especially Ulos. In this field, multidisciplinary collaboration is needed. Collaborative arts and traditional Ulos weaving skills combined with technological sophistication can help facilitate the design process and develop weaving designs.

The development of the industrial revolution, Ulos can be seen as an element of production undergoing transformation, called that the globalization process which penetrated all aspects of life so that the cultural elements between one society and other communities increasingly culturally similar, starting from the motif type, their motif and designations. DiTenun prepares ourselves in the era of industry 4.0 by trying to create or produce Ulos motifs, motif adapted from fractal formulas, involving weaver resources, fostering the resources of weavers or un empowered communities so that weavers can broaden income and sales of production.

\subsection{Application Analysis and Design}

Image processing with machine learning studies the motifs of weaving and produces new motifs with a way as shown in Figure 1. 


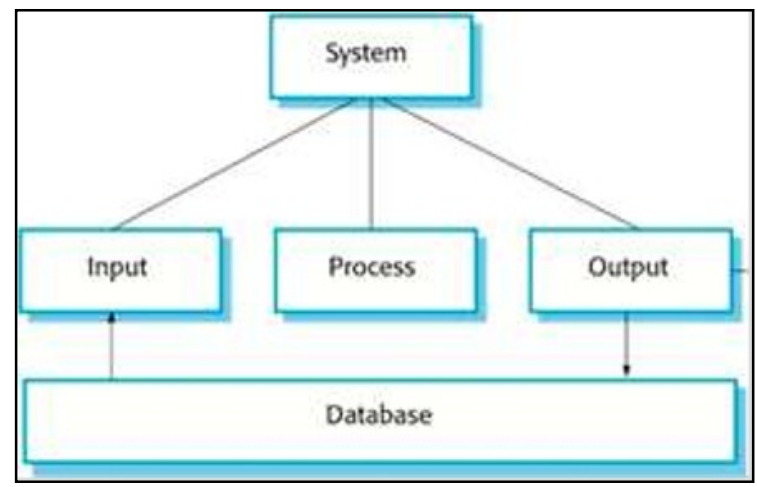

Fig. 1. DiTenun Design

Ulos motif data will be stored in the database. The Ulos motif that already exist today will be sent as output to the system and processed with image processing to produce output in the form of new motif. There are several motif that can be produced. To get other motif, motif that have been successfully generated can be saved to the database. Motif will be sent as input in the system and do image processing and produce and other motif.

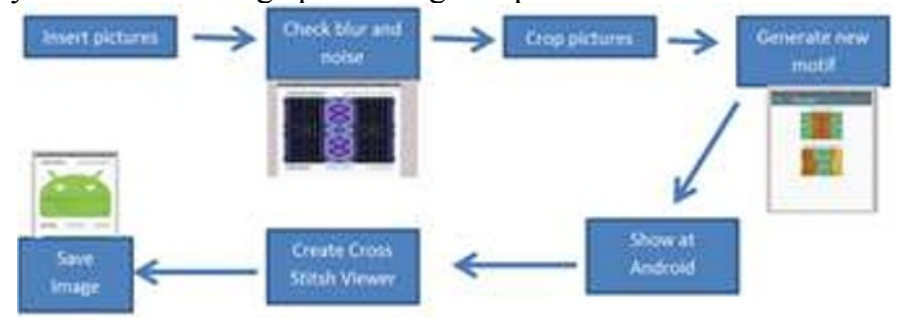

Fig. 2. Generating Motif Process

As depicted in Figure 2, motif images can be edited to get the image the weaver wants. The image will be processed to produce a new motif. The results of new motifs can bedisplayed on Android applications. New motifs generated by the system will be given to weavers as new ideas to produce new Ulos motifs. Weavers are educated to weave Ulos neatly in accordance with predetermined standards so that they are suitable for commercialization.

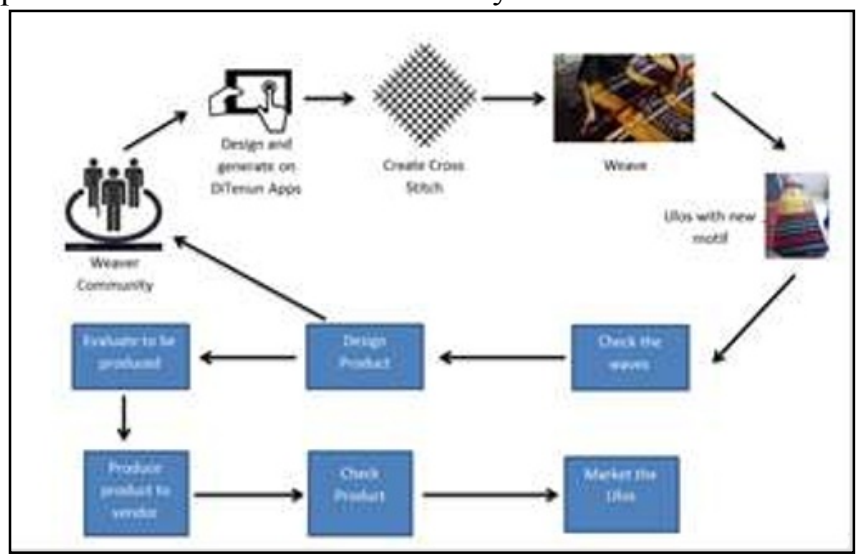

Fig. 3. DiTenun Program

To produce Ulos, a more creative item requires creativity and effort from the community of craftsmen themselves. The workflow for producing an item that is marketable is to produce 
woven fabrics with motifs that have been produced by smart devices. The new woven fabric will be examined for details of neatness and conformity with the framework. Crafters will design products that want to be made with these fabrics such as bags or clothes. The design and woven fabric will be evaluated to check the feasibility of production before being given to the vendor. After passing the feasibility evaluation, the fabric design can be given to the vendor for processing. After completion of production, the product will be reexamined for feasibility before being sold. Figure 3 presents the flow of tasks to generate new motifs using DiTenun.

\subsection{DiTenun Business Analysis}

As mentioned, DiTenun is created to support small and medium scale industry, particularly woven clothes industry across Indonesia. By using DiTenun to have new motifs, weavers are expected to able more various designed of clothes that can be adjusted to the market preference. We also provide online system www.ditenun.com that having features to generate and choose your own motif, and then ordering products using the new motif. The online system is also designed as a market place for the weavers to commercialize their products.

We have disseminated DiTenun to Ulos weavers from several regions around Toba area through workshops and training. Based on the meetings, we develop a SWOT analysis of the possible development and implementation of the business continuity of the motif of DiTenun in the industrial era 4.0, the results of SWOT, as follows.

Strengths:

a. Districts on the outskirts of Lake Toba are familiar with Ulos craftsmen (weavers).

b. Mothers and young women usually choose to be weavers rather than farmer in Toba lake region.

c. Weaver communities have used smart phones

d. Weaver communities welcome the development of various motif.

e. New motif training is easy to implement.

f. The local government supports the training program and strengthening the Ulos weaving organization with the motif of DiTenun.

Weaknesses:

a. The price of community-woven Ulos is relatively very cheap.

b. A lot of agents trapping the weavers.

c. The monotonous Ulos motif is only for customary purposes.

d. Allotment of Ulos woven products is only for ceremony cultures, Batak people in general.

e. Lack of connection to the broad market.

Opportunities:

a. Penetration of telecommunications networks is getting better, can reach remote locations of weavers.

b. Production of Ulos with the development of motifs of DiTenun is easily expanded.

c. Contribution of Local Government in supporting village training movements.

d. The industrial organization of post-weave Ulos fabrics is easy to obtain.

e. Broader target market achievement through sharing various functions and Ulos motifs.

f. Ulos are known worldwide.

g. Technology influences the people rapidly, example smartphone and internet.

Threats:

a. Industrial development from motif is not Ulos

b. Some people's views about Ulos is idealism 
c. Teenagers are more likely to not like living in the village but rather migrate and do other work. Using the Template

From the analysis, we have to work hard to alleviate weakness and threats and make use the strengths and opportunities to disseminate DiTenun to empower Ulos weavers around Toba. This analysis can also then be used in replicating the use of DiTenun to other types of traditional woven clothes.

\section{RESULT AND DISCUSSION}

The results of Weaving can have an impact on the technology produced and on the social life and culture of the weavers.

\subsection{DiTenun Technology}

\subsubsection{DiTenun Mobile Application}

DiTenun is a smart device using image processing techniques that learn about image dots and take patterns so that they are able to generate new motifs from existing motifs. The development of smart devices already exists in the mobile version. This application has an existing weaving image browsing feature, and runs module pattern generation with image pattern with constant parameters. Nowadays smart devices can run the image pattern with various different parameters (users can customize function parameters) so that from an original image can be produced a variety of different motif using the three techniques that different.

In addition, the interface development process runs iteratively to get frequent and continuous feedback. In addition, a technical method for teaching these smart devices is also needed to crafters. This teaching is needed so that the knowledge of how to use this smart device can be realized properly. The appearance of this application is shown in the Figure 4.

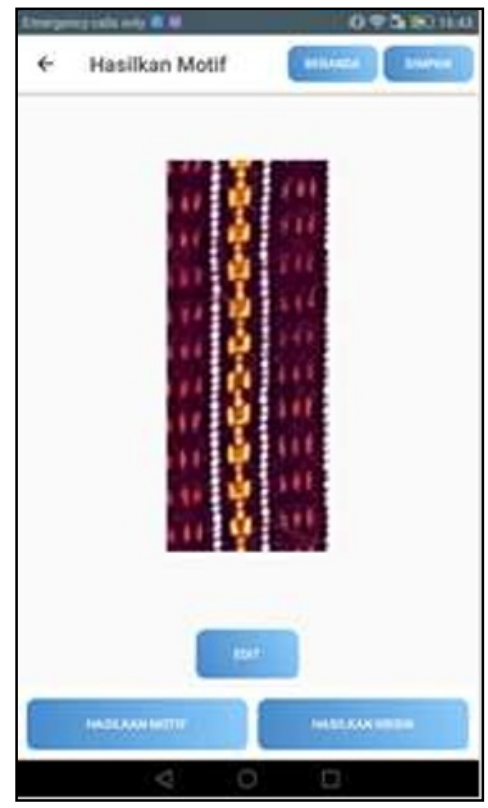


Fig. 4. DiTenun Mobile Application

The application is not only able to produce new motifs but can be poured in a cross stitch form according to the calculation. The resulting cross stitches are then used by weavers as a base for weaving.

\subsubsection{DiTenun Web}

Besides being available in the mobile application, DiTenun is available on web applications that can be accessed on the link: http://DiTenun.com/. Web development is a medium for exchanging information. Not only as a media that produces information about Ulos, the DiTenun Web is also designed as a medium for buying and selling products produced by the Weaving application.

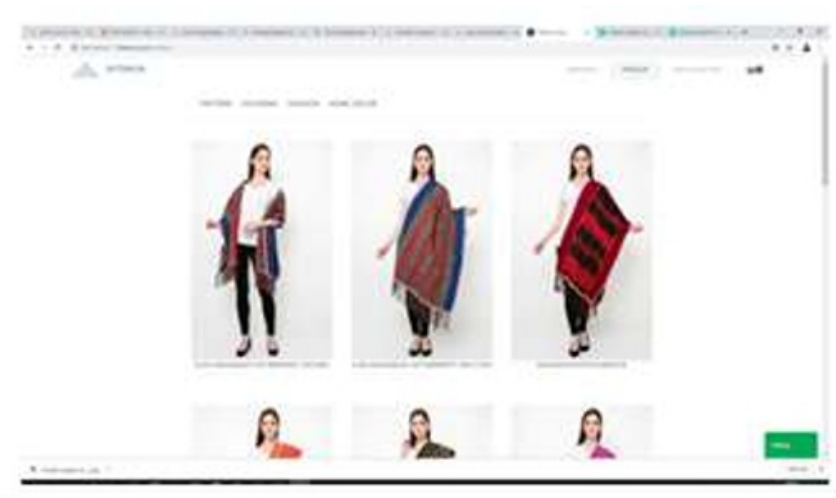

Fig. 5. DiTenun Website

There are several products that are ready for commercialization, including:

a. Motif Collection Book (hardcopy \& softcopy)

b. One Unit Motif (hardcopy \& softcopy)

c. Souvenirs (Local and IT Del Souvenirs)

d. Corporate Merchandises (pre order)

e. Fashion Collection (seasonal products)

f. Home Décor Collection (seasonal product)

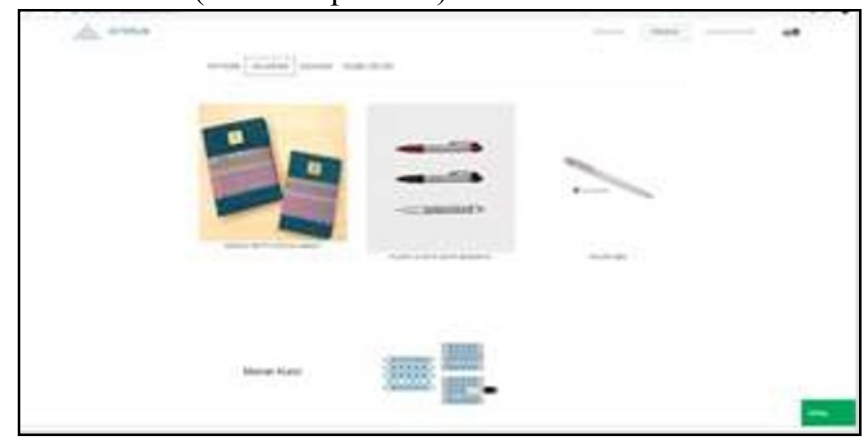

Fig. 6. DiTenun Product 


\subsection{Weaver Cultures and Social}

Implementation of sustainability of a production, starting from: Establishing industrial boundaries, whose purpose focus more, make standards, determine locations and strengthen human resources (Moisa, 2017). In line with Filip (2018), the implementation of sustainability starts from communication and cooperation between technology users, information providers, and information technology systems that can be used in real time. Enables flexible production at lower costs and designs business models. Creating a global network, with the Environmental Management System (EMS) (Yusoff \& Rudolf, 2015).

The presence of DiTenun has had the following positive impact.

a. The development of Ulos cultivation business is a prospective livelihood and has a legality principle.

b. Increased technological capacity that will have a huge impact on developing their business going forward Impacts and benefits for partners.

c. Ensure the survival of Ulos artisans through a permanent and sustainable financial income.

d. Ensure weaving skills Ulos is not lost and can develop continuously from generation to generation

\section{CONCLUSION}

DiTenun is a smart application that can produce Ulos motifs by using image processing with image pattern techniques. Ulos motifs are generated from existing motifs so that they still contain the values contained in Ulos. Ulos motif that has a value is possible to be generated using DiTenun application. The new motif enables flexible production at lower costs and designs business models. There are several products that are ready for commerlization and increase the weaver income. The presence of DiTenun is very precisely in the industrial 4.0 era by utilizing technology to enhance creativity, to increase economy and to keep culture values.

\section{References}

1. S. Angra and S. Ahuja, in Proc. 2017 Int. Conf. Big Data Anal. Comput. Intell. ICBDACI 2017 (2017), pp. 57-60

2. G. Anríquez and K. Stamoulis, Rural Development and Poverty Reduction (2007)

3. S. Aritonang, J. Online Mhs. Fak. Ekon. Univ. Riau 2, 33710 (2015)

4. A. C. Barus, R. Panggabean, A. Sinaga, and Y. Manik, Lemb. Ris. Inst. Teknol. Bandung (2015)

5. W. Bauer, S. Schlund, T. Hornung, and S. Schuler, Logforum 14, 341 (2018)

6. C. M. Bishop, Machine Learning and Pattern Recognition (Springer-Verlag New York Inc., New York, United States, 2006)

7. R. C. Gonzalez, New Jersey 07458 Prentice Hall (n.d.)

8. C. O. Moisă, Valahian J. Econ. Stud. 8, 2017 (2017)

9. Y. A. Piliang, Dunia Yang Dilipat: Tamasya Melampaui Batas-Batas Kebudayaan (Matahari, Bandung, 2011)

10. J. W. G. Putra, Pengenalan Konsep Pembelajaran Mesin, 9th ed. (Institut Teknologi Bandung, Bandung, 2017)

11. R. Sathya and A. Abraham, Int. J. Adv. Res. Artif. Intell. 2, 34 (2013)

12. C. TOMA and M. POPA, Inform. Econ. 22, 46 (2018)

13. S. Yusoff, R. Nordin, and H. Yusoff, Issues Soc. Environ. Account. 9, 18 (2015)13. S. Angra and S. Ahuja, in Proc. 2017 Int. Conf. Big Data Anal. Comput. Intell. ICBDACI 2017 (2017), pp. 57-60 